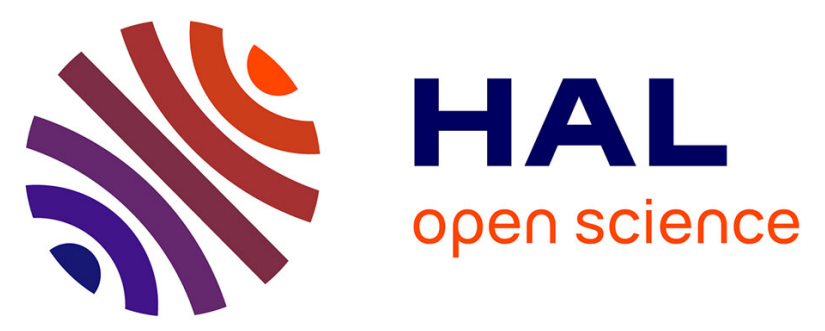

\title{
New mannose derivatives: The tetrazole analogue of mannose-6-phosphate as angiogenesis inhibitor
}

Cătălina Ionescu, Simona Sippelli, Loic Toupet, Véronique Barragan-Montero

\section{To cite this version:}

Cătălina Ionescu, Simona Sippelli, Loic Toupet, Véronique Barragan-Montero. New mannose derivatives: The tetrazole analogue of mannose-6-phosphate as angiogenesis inhibitor. Bioorganic and Medicinal Chemistry Letters, 2016, 26 (2), pp.636-639. 10.1016/j.bmcl.2015.11.059 . hal-01259520

HAL Id: hal-01259520

https://hal-univ-rennes1.archives-ouvertes.fr/hal-01259520

Submitted on 22 Jan 2016

HAL is a multi-disciplinary open access archive for the deposit and dissemination of scientific research documents, whether they are published or not. The documents may come from teaching and research institutions in France or abroad, or from public or private research centers.
L'archive ouverte pluridisciplinaire HAL, est destinée au dépôt et à la diffusion de documents scientifiques de niveau recherche, publiés ou non, émanant des établissements d'enseignement et de recherche français ou étrangers, des laboratoires publics ou privés. 
New mannose derivatives: the tetrazole analogue of mannose-6phosphate as angiogenesis inhibitor

Cătălina Ionescu, Simona Sippelli, Loïc Toupet, Véronique Barragan-Montero
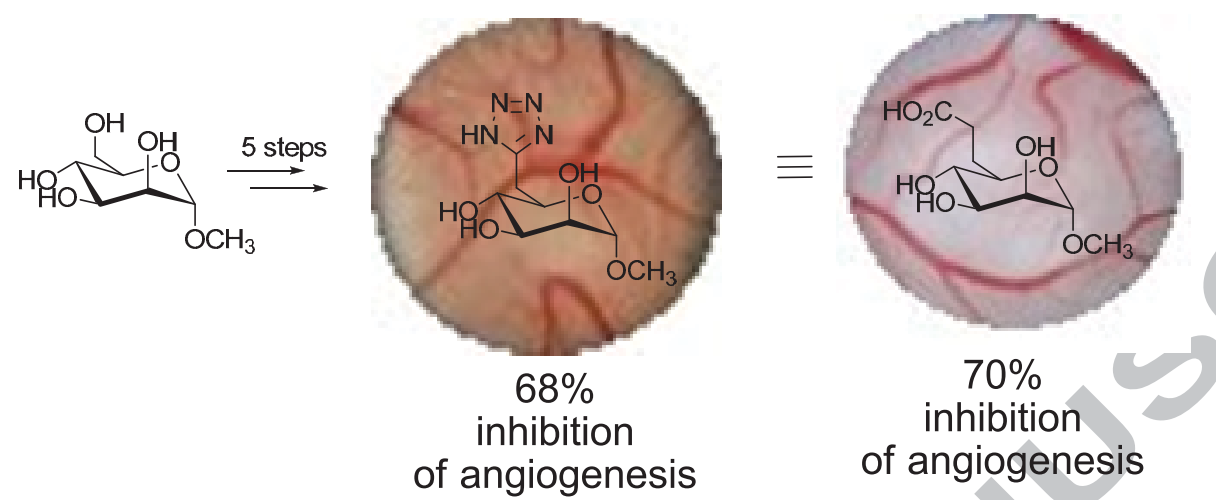


\title{
New mannose derivatives: the tetrazole analogue of mannose-6- phosphate as angiogenesis inhibitor
}

\author{
Cătălina Ionescu ${ }^{\mathrm{a}, 1, *}$, Simona Sippelli ${ }^{\mathrm{a}}$, Loïc Toupet ${ }^{\mathrm{b}}$, Véronique Barragan-Montero $^{\mathrm{a}}$ \\ ${ }^{a}$ Institut Charles Gerhardt (ICGM) UMR 5253, Université de Montpellier, place Eugène Bataillon, 34095 Montpellier \\ Cedex 5, France \\ ${ }^{b}$ GMCM UMR 6626 Campus de Beaulieu 35042 Rennes Cedex, France \\ * Corresponding author. Tel/ Fax: +40 757571 247; e-mail address: catalinagurgui@yahoo.co.uk (C. Ionescu)
}

\begin{abstract}
Two novel compounds with mannose-derived structure, bearing a tetrazole (compound 3) and a sulfone group (compound 4) in terminal position, have been prepared from methyl $\alpha$-D-mannopyranoside in reduced number of steps. The angiogenic activity of $\mathbf{3}$ and $\mathbf{4}$ has been screened using the chick chorioallantoic membrane (CAM) method. Tetrazole $\mathbf{3}$ has been identified to possess a promising bioactivity, being identified as angiogenesis inhibitor, with $68 \%$ of neovascular vessels when compared to control (PBS).
\end{abstract}

Keywords: mannose-6-phosphate analogues/ iodination / carboxylic acid / tetrazole / sulfone

Angiogenesis is the process of generating new capillary blood vessels from pre-existing ones. ${ }^{1}$ In healthy adults, angiogenesis is normally absent, excepting two specific phenomena: the cutaneous wound healing ${ }^{2}$ and the intervention in female reproductive functions. ${ }^{3,4}$ An abnormal vascularisation (either insufficient, either excessive) can cause or contribute to the development of various diseases. ${ }^{5}$ Therefore, angiogenesis activators have wide applications in medicine, in the treatment of diseases caused by insufficient angiogenesis, linked to the ischemia of a part of the vascular system. At the same time, a considerable amount of attention has been dedicated to angiogenesis inhibitors, due to their intensive employment, among other therapeutic applications, in cancer treatment. It has been demonstrated that tumors cannot develop to a volume bigger than 1-2 $\mathrm{mm}^{3}$ without the participation of blood vessels. ${ }^{6}$ Therefore, angiogenesis inhibitor therapy ${ }^{7}$ became an important actor in cancer therapy. It is supposed hat angiogenesis inhibitors act by inhibiting the development of blood vessels inside tumors and by normalizing the blood vessel network, facilitating the access of medication at tumor site.

Angiogenesis is a complex process, involving numerous biological mediators. ${ }^{8}$ Recent studies indicate that the cation-independent mannose-6-phospahte receptor (CI-M6PR) is also involved in angiogenesis. ${ }^{9,10}$ CI-M6PR, also known as the mannose-6-phosphate/insulin like growth factor II receptor (M6P/IGFIIR), is a $275 \mathrm{KDa}$, P-type glycoprotein, ${ }^{11}$ whose main function is represented by the transport of newly synthesized enzymes from the cell membrane or from Golgi apparatus to lysosomes. ${ }^{12}$ The binding specificity of the receptor has been intensively studied. ${ }^{13}$ In our ongoing research on mannose-6-phosphate (M6P) and its derivatives, different M6P analogues have been synthesized and their affinity for the M6P/IGFIIR has been tested. ${ }^{14-17}$ In a recent study, we have reported the synthesis of different M6P analogues, bearing various

\footnotetext{
${ }^{1}$ Present address: Faculty of Sciences (Chemistry Department), University of Craiova, 107 I Calea București, 200144 Craiova, Romania
} 
functional groups (azido, aminomethyl, carboxyl, malonate, sulfonate, carboxymethyl, phosphonate) in the C6 position of the carbohydrate and a methyl group in anomeric position, using a method involving a key cyclic sulfate intermediate. The angiogenic activity of these compounds has been evaluated and the tested analogues proved to be angiogenesis regulators. ${ }^{18}$ The most potent angiogenesis inhibitor in this series was the methyl mannopyranoside of M6P itself (MeM6P) (compound 1, Figure 1), but its therapeutic applications are limited by its instability in biological environment, caused by the presence of hydrolytic enzymes. Besides MeM6P, another compound with promising antiangiogenic properties was the carboxylic acid 2. Because tetrazoles are known as nonclassical bioisosters of carboxylic acids, ${ }^{19,} 20$ the evaluation of the angiogenic properties of compound $\mathbf{3}$ became an interesting target, presented in this paper. At the same time, we prepared a second mannose-6-functionalized derivative: the sulfone 4 . Sulfones have previously been investigated as phosphate mimics in carbohydrate series, both in the anomeric ${ }^{21}$ and terminal position of carbohydrates, when a dimethylene sulfone linker has been used as a replacer of the phosphodiester group in oligonucleotides. ${ }^{22}$ Compound $\mathbf{4}$ is not a bioisostere of M6P. It has heteroatoms in the C6 position, but, unlike other M6P analogues tested by now, it does not possess negatively charged groups in the C6 position at physiologic $\mathrm{pH}$. Moreover, besides the biological applications of $\mathbf{4}$, intermediate 5, which is used for the preparation of the final compound 4, can open important perspectives in the synthetic carbohydrate chemistry. Carbanions of methylene groups in $\alpha$ position of sulfones can react with a variety of electrophiles, like for example carbonyl compounds, followed by subsequent elimination of the sulfone using samarium diiodide or sodium/mercury amalgam ${ }^{23}$ (Julia olefination method). ${ }^{24}$

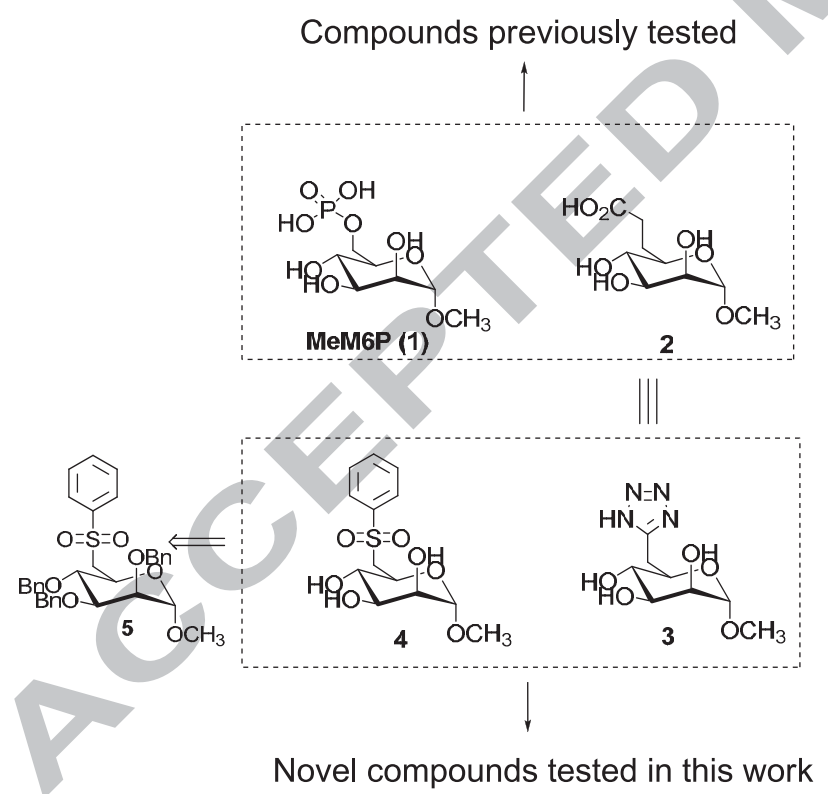

Figure 1. Mannose derivatives functionalized in terminal position.

In order to prepare compounds $\mathbf{3}$ and $\mathbf{4}$, we have chosen an efficient pathway that involves the iodinated compound $\mathbf{7}$ as common intermediate in the synthesis of the desired carbohydrates (Scheme 1). This intermediate was obtained from methyl $\alpha$-D-mannopyranoside, using an Appel reaction $^{25}$ and among various protocols available ${ }^{26-28}$ we have chosen the procedure of 
Skaanderup et al., ${ }^{26}$ followed by introduction of benzyl protective groups on carbohydrate hydroxyls. Because benzylation under standard basic conditions (benzyl bromide and sodium hydride or potassium hydroxide) is not compatible with our iodinated compound, we have realized this step in acid catalysis ${ }^{26}$ with benzyl trichloroacetimidate prepared from benzyl alcohol and 1,1,1-trichloroacetonitrile. ${ }^{29}$ The benzylation reaction is usually realized with triflic acid as catalyst, but our tests with boron trifluoride diethyletherate ( 0.3 equiv/hydroxyl group) have given the same result.

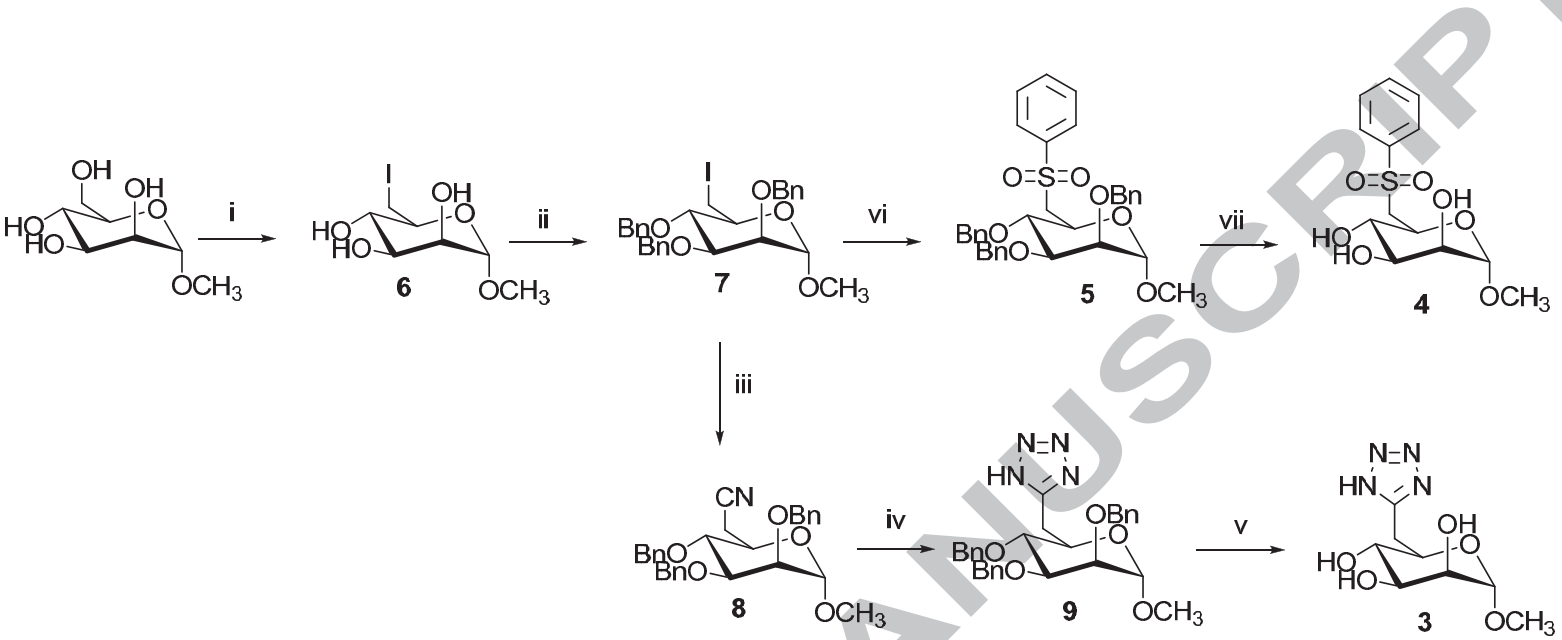

Scheme 1. Synthesis of $\mathbf{3}$ and 4. Reactions, conditions and yields: (i) $\mathrm{I}_{2}, \mathrm{PPh}_{3}$, Imidazole, THF, $2 \mathrm{~h}$ at refluxing temperature, $81 \%$; (ii) benzyl trichloroacetimidate, triflic acid, dioxane, $10 \mathrm{~min}$ at $0^{\circ} \mathrm{C}, 67 \%$; (iii) $\mathrm{NaCN}, \mathrm{DMF}, 2 \mathrm{~h}$ at $70^{\circ} \mathrm{C}, 87 \%$; (iv) $\mathrm{NaN}_{3}, \mathrm{NH}_{4} \mathrm{Cl}, \mathrm{DMF}, 144 \mathrm{~h}$ at $95^{\circ} \mathrm{C}, 70 \%$; (v.a) $\mathrm{BCl}_{3}, \mathrm{CH}_{2} \mathrm{Cl}_{2}, 3 \mathrm{~min}$ at $-78^{\circ} \mathrm{C}$; (v.b) $\mathrm{SOCl}_{2}$, methanol, $3 \mathrm{~h}$ at r.t. ; $36 \%$ over the two steps v.a and v.b; (vi) sodium phenylsulfinate, DMF, $12 \mathrm{~h}$ at $60^{\circ} \mathrm{C}, 67 \%$; (vii) $\mathrm{H}_{2}, \mathrm{Pd} / \mathrm{C}$, ethyl acetate/methanol, $\mathrm{HCl}, 2 \mathrm{~h}$ at r.t., $80 \%$.

The tetrazole derivative $\mathbf{3}$ was prepared using the nitrile intermediate $\mathbf{8}$, obtained by reacting 7 with sodium cyanide in DMF. The conversion of nitriles to tetrazoles supposes, in a classical manner, the usage of hydrazoic acid, prepared from sodium azide and acids ${ }^{30}$ or of tributyltin azide, prepared from sodium azide and tri- $n$-butyltin chloride. ${ }^{31}$ Other methods include the usage of $\mathrm{Al}\left(\mathrm{N}_{3}\right)_{3}$, prepared in situ from trimethylaluminium and trimethylsilyl azide $\mathrm{s}^{32}$ or salts of hydrazoic acid. ${ }^{33}$ We decided to use the last method, already applied with success in glucose series, using sodium azide and ammonium chloride, that allowed us to obtain the tetrazole 9 in $70 \%$ yield. The last step was represented by carbohydrate hydroxyl groups' deprotection. Based on our knowledge, no literature data has reported by now the synthesis of an unprotected glycoside bearing a tetrazole moiety in terminal position. In our case, the deprotection of mannose hydroxyl groups proved to be very delicate. Initial attempts of classical hydrogenolysis at different hydrogen pressures, in neutral or acidic solvents, were inefficient. Another method known for benzyl groups deprotection is represented by the action of boron trichloride. ${ }^{34}$ The usage of this compound in methyl glycosides remains limited, as $\mathrm{BCl}_{3}$ is known to break glycosidic bonds. ${ }^{35}$ Indeed, by reacting 9 with $\mathrm{BCl}_{3}$ in $\mathrm{CH}_{2} \mathrm{Cl}_{2}$, at $-78^{\circ} \mathrm{C}$, the tetrazole mannopyranoside 3 has been obtained, but together with its corresponding mannopyranose, bearing a hydroxyle group in anomeric position (Scheme 2). The crude reaction mixture has been methylated, using the $\mathrm{SOCl}_{2} / \mathrm{MeOH}$ couple, in order to enrich the mixture in the desired derivative 3 . 


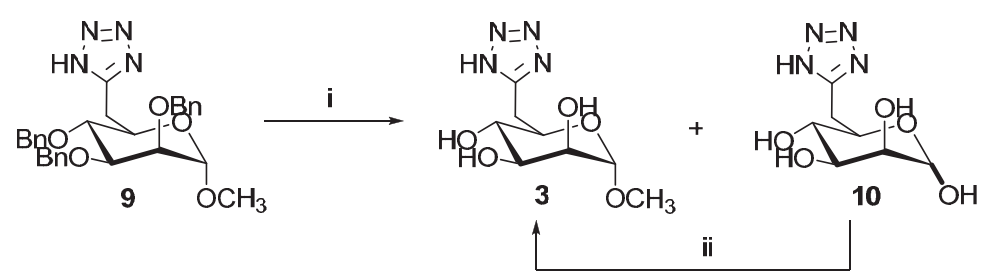

Scheme 2. Two-steps synthesis of $\mathbf{3}$, by deprotection of hydroxyl groups of $\mathbf{9}$ followed by methylation of the obtained reaction mixture. Reactions, conditions and yields: (i) $\mathrm{BCl}_{3}, \mathrm{Cl}_{2} \mathrm{H}_{2} ; 3$ min at $-78^{\circ} \mathrm{C}$; (ii) $\mathrm{SOCl}_{2} / \mathrm{MeOH}, 3 \mathrm{~h}$ at r.t.; $36 \%$ over the two steps (i) and (ii).

The sulfone $\mathbf{4}$ has been prepared in two steps starting from 7: displacement of iodine with p-toluenesulfinate ${ }^{36}$ and benzyl groups' elimination (Scheme 1). Because initial attempts of deprotection by hydrogenolysis at neutral $\mathrm{pH}$ were inefficient, this step was realized in the presence of $\mathrm{HCl}$ in order to obtain compound 4. Single-crystal X-ray analysis of 5 confirmed its structure. Crystallographic data (excluding structural factors) for the structure of compound $\mathbf{5}$ have been deposited at the Cambridge Crystallographic Data Centre with the deposition number CCDC 679336. An ORTEP diagram of $\mathbf{5}$ is shown in Figure 2.

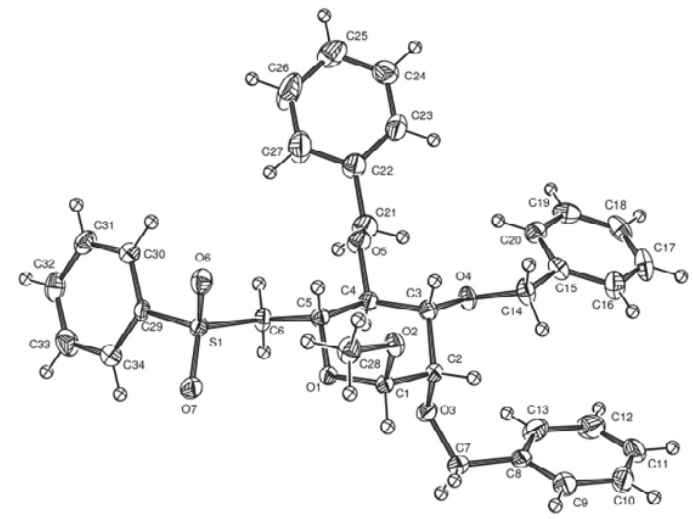

Figure 2. ORTEP drawing of 5.

The angiogenic properties of the two products $\mathbf{3}$ and $\mathbf{4}$ were investigated in vivo using the chick chorioallantoic membrane (CAM) assay. ${ }^{37,18}$ Besides the two compounds $\mathbf{3}$ and $\mathbf{4}$, MeM6P and its phosphonate analogue $\mathbf{1 0}$ have been used as angiogenesis inhibitor and activator, respectively. A phosphate-buffered saline (PBS) control experiment has also been realized. Membranes treated with the mentioned compounds were placed on nascent CAM during the $7^{\text {th }}$ embryonic day and were grown in ovo at $38^{\circ} \mathrm{C}$ for 4 days. Angiogenic response quantification was realized by measuring the area of neovascularization on the surface of each membrane used in the tests. The results of the experiment were in good agreement with our expectations: no effect on agiogenesis could be noticed in the case of sulfone $\mathbf{4}$, while tetrazole $\mathbf{3}$ showed an inhibitory effect on angiogenesis. Its inhibitory properties evaluated using this method were very similar with those of its carboxylic acid analogue 2 reported earlier ${ }^{11}$ (68\% of neovascular vessels for $\mathbf{3}$ and $70 \%$ of neovascular vessels for $\mathbf{2}$, the PBS control being defined as 100\%) (Figure 3). 


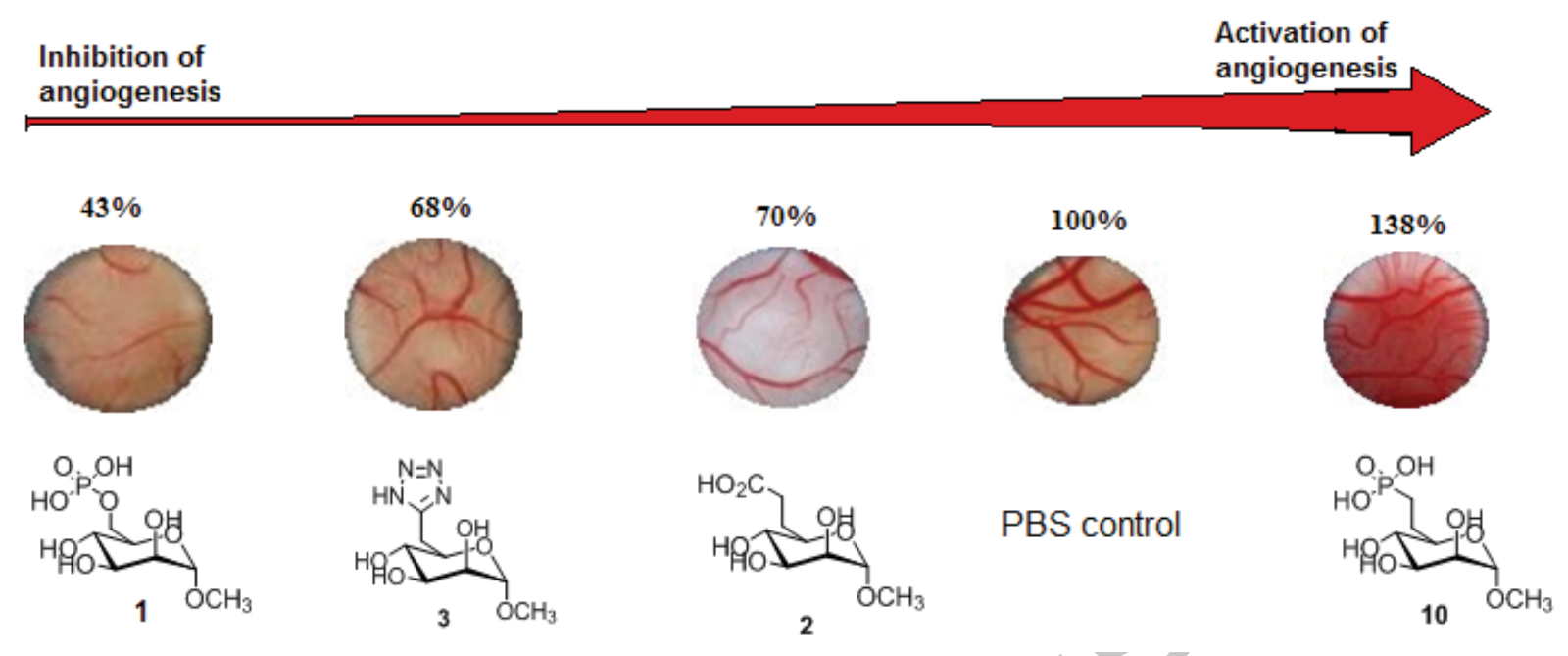

Figure 3. Chorioallantoic membrane (CAM) assays realized with MeM6P (1) as inhibitor, its phosphonate analogue $\mathbf{1 0}$ as angiogenesis activator, PBS as control, carboxylic acid $\mathbf{2}$ and its non-classical bioisostere, tetrazole 3. The given values represent the extent of angiogenesis, $100 \%$ being the value quoted for PBS (control).

In conclusion, two novel compounds have been reported in this paper: the sulfone $\mathbf{4}$ and the tetrazole 3. They have both been prepared starting from methyl $\alpha$-D-mannopyranoside, using methyl 6-deoxy-6-iodo- $\alpha$-D-mannopyranose as common intermediate, in six steps for tetrazole 3 (12\% yield) and in four steps for sulfone 4 (29\% yield). Both products' angiogenic activity has been evaluated using the CAM assay. Tetrazole $\mathbf{3}$ showed good inhibitory properties (70\% compared to PBS), thus being an interesting new carbohydrate derivative with possible applications in anticancer theraphy. Moreover, this discovery is important because the number of monosaccharides with angiogenesis inhibitor properties reported by now is extremely limited. ${ }^{18}$

\section{Acknowledgment}

This work was supported by the Ministère de la Recherche et de la Technologie (MRT).

\section{Supplementary data}

Supplementary data associated with this article can be found in the online version, at.................................

\section{References and notes}

1. Carmeliet P. Nat. Med. 2003, 9, 653.

2. Singer, A. J.; Clark, R. A. N. Engl. J. Med. 1999, 341, 738.

3. Groothius, P. G. Angiogensis 2005, 8, 87.

4. Gargett, C. E.; Rogers, P. A. W. Reproduction 2001, 121, 181.

5. Folkman, J.; Shing, Y. J. Biol. Chem. 1992, 267, 10931. 
6. Folkman, J. N. Engl. J. Med. 1971, 285, 1182.

7. Quesada, A. R.; Munoz-Chapuli,R.; Medina, M. A. Med. Res. Rev. 2006, 26, 483-530.

8. Liekens, S.; De Clercq, E.; Neyts, J. Biochem. Pharmacol. 2001, 61, 253-270.

9. Volpert, O.; Jackson, D.; Bouck, N.; Linzer, D. I. H. Endocrinology, 1996, 137, 3871.

10. Wood, R. J.; Hulett, M. D. J. Biol. Chem. 2008, 283, 4165.

11. For a review on animal lectins, see: D. C. Kilpatrick Biochim. Biophy. Acta, General Subjects 2002, 1572, 187.

12. For a review on the mannose 6 - phosphate /insulinlike growth factor II receptors, see: S. Kornfeld Annu. Rev. Biochem. 1992, 61, 307.

13. Distler, J. J.; Guo, J.; Jourdian, G. W.; Srivastava, O. P.; Hindsgaul, O. J. Bio. Chem. 1991, 266, 21687.

14. Vidil, C.; Morère, A.; Garcia, M.; Barragan, V.; Hamdaoui, B.; Rochefort, H.; Montero, J.-L. Eur. J. Org. Chem. 1999, 447.

15. Vidal, S. ; Vidil, C.; Morere, A.; Garcia, M.; Montero, J.-L. Eur. J. Org. Chem. 2000, 20, 3433.

16. Vidal, S.; Garcia, M.; Montero, J.-L.; Morere, A. Bioorg. Med. Chem. 2002, 10, 4051.

17. Jeanjean, A.; Garcia, M.; Leydet, A.; Montero, J.-L.; Morere, A. Bioorg. Med. Chem. 2006, 14, 3575.

18. Barragan-Montero, V.; Awwad, A.; Combemale, S.; de Santa Barbara, P.; Jover, B.; Molès, J.-P.; Montero, J.-L. ChemMedChem. 2011, 6, 1771.

19. Patani, G. A.; Lavoie, E. J. Chem. Rev. 1996, 96, 3147.

20. Thornber, C. W. Chem. Soc. Rew. 1979, 8, 563.

21. Centrone, C. A.; Lowary, T. L. Bioorg. Med.Chem. 2004, 12, 5495.

22. Blattler, M.O.; Wenz,C.; Pingoud,A.; Benner, S.A. J. Am. Chem. Soc. 1998, 120, 2674.

23. Keck, G. E. ; Savin, K. A.; Weglarz, M-A. J. Org. Chem. 1995, 60, 3194.

24. Dumeunier, M. E. Istvan Modern Carbonyl Olefination 2004, 104.

25. Appel, R. Angew. Chem. Int. Ed. Engl. 1975, 14, 801-811.

26. Skaanderup, P. R.; Poulsen, C. S.; Hyldtoft, L.; Jorgensen, M. R.; Madsen, R. Synthesis 2002, 12, 1721.

27. Classon, B.; Liu, Z.; Samuelsson, B. J. Org. Chem. 1988, 53, 6126.

28. Garegg, P. J.; Samuelsson, B. J. Chem. Soc. Perkin Trans. 1 1980, 12, 2866.

29. Kato, D.; Mitsuda, S.; Ohta, H. J. Org. Chem. 2003, 68, 7234.

30. Herbst, R. M.; Wilson, K. R. J. Org. Chem. 1957, 22, 1142. 
31. Duncia, J. V.; Pierce, M. E. ; Santella, J. B. J. Org. Chem. 1991, 56, 7, 2395.

32. Huff, B. E.; Staszak, M. A. Tetrahedron Lett., 1993, 34(50), 8011.

33. Pedrosa, M. T. C.; Alves, R. B.; Prado, M. A. F.; Filho, Dias de Souza J.; Alves, R. J.; D'Accorso, N. B.. J. Carbohydr. Chem. 2003, 22, 433.

34. Terinek, M.; Vasella, A. Helv. Chem. Acta, 2003, 86, 3482.

35. Nishiharal, M.; Koga, Y. J. Lipid Res. 1988, 29, 384.

36. Lindberg, B.; Lundstrom. H. Acta Chemica Scandinavica 1966, 20(9), 2423.

37. Hasan, J.; Schnyder, S. D.; Bibby, M.; Double, J. A.; Bicknel, R.; Jayson, G. C. Angiogenesis 2004, 7, 1. 